\title{
Blood pressure variability analysis enhances risk stratification in chronic heart failure
}

\author{
Matthias Goernig ${ }^{1 *}$, Rico Schroeder ${ }^{2}$, Robby Kleindienst ${ }^{3}$, Hans Reiner Figulla ${ }^{3}$, Andreas Voss ${ }^{2}$ and Uwe Leder $^{3}$ \\ *Correspondence: Matthias.Goernig@med.uni-jena.de

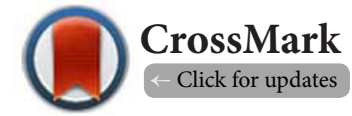 \\ ${ }^{1}$ Clinic of Geriatrics, HELIOS Klinikum Aue, Germany. \\ ${ }^{2}$ Department of Medical Engineering, University of Applied Sciences, Jena, Germany. \\ ${ }^{3}$ Clinic of Internal Medicinel, University Hospital of Jena, Germany.
}

\begin{abstract}
Chronic heart failure (CHF) alters heart rate and blood pressure variability (HRV, BPV). Additional prospective studies are needed to clarify their role in cardiac risk stratification. The aim of this study was to prove the value of BPV analysis for risk stratification in CHF compared to HRV. In 88 patients with CHF high-resolution ECG (22 bit resolution, $1600 \mathrm{~Hz}$ sampling frequency) and continuous non-invasive blood pressure (NIBP, 22 bit, $500 \mathrm{~Hz}$ ) were recorded over 30 minutes. Based on volume clamp method the peripheral arterial blood pressure was measured via finger cuff. From the ECG recordings, time series of beat-to-beat intervals were extracted to analyze HRV and from the NIBP recordings, time series of systolic as well as diastolic blood pressure values were extracted to analyze BPV. To get 'normal-to-normal' beat time series (NN), ventricular premature beats and artefacts within the time series were detected and replaced by interpolated normal heartbeats. Standard HRV and systolic as well as diastolic BPV parameters were evaluated for patients with ejection fraction above and below 40\% (EF+ and EF-) and for 5-year follow up (cardiac death and worsening of NYHA class). Only one HRV parameter (MEAN NN) but six BPV indices separated EF+ from EF-. In the 5-year follow up systolic BPV but not ejection fraction and HRV predicted worsening of NYHA class with $15 \%$ positive and $91.2 \%$ negative predictive value. Cardiac death was predicted in $81.8 \%$ by using the two best diastolic BPV parameters (dLF/HF and dSDNN). We conclude BPV analysis may be useful in medium range risk stratification in patients with CHF. The analysis of autonomic control should focus more on blood pressure regulation.
\end{abstract}

Keywords: Blood pressure variability, heart rate variability, chronic heart failure, risk stratification

\section{Introduction}

Outcomes related to chronic heart failure (CHF) remains very poor: mortality is related to its severity ranging from 5 to $10 \%$ in patients with mild to $30-40 \%$ in severe cases $[1,2]$. The main cause of death in CHF is related to arrhythmic events and these patients are also at risk for sudden cardiac death. Evidence suggests that implantable cardioverter defibrillators (ICD) reduce total mortality in CHF but may be cost-effective in some subgroups of patients at high risk [3]. So far, recommendation for ICD implantation is primary based on the left ventricular ejection fraction (EF). Further research is needed for risk stratification of patients in whom ICD are most likely to be clinically and cost-effective.

Clinical importance of autonomic control became apparent since the late 1980s when it was confirmed that HRV was a strong and independent predictor of mortality following an acute myocardial infarction. With the availability of high frequency 24-h multi-channel electrocardiographic recorders, HRV has the potential to provide additional valuable insight into physiological and pathological conditions and to enhance risk stratification in different cardiac diseases [4]. Whereas most of the studies on autonomic control were performed by HRV analysis, less is known about the role of BPV. Beat to beat registration of systolic and diastolic blood pressure was evaluated in different cardiac diseases. There is a significant correlation to baroreflex sensitivity in patients with hypertension independent to their age and systolic blood pressure [5] and there are also data about the increase of BPV in early stage of hypertension [6]. Additional to ischemic cardiomyopathy, hypertensive heart disease and dilated cardiomyopathy [7-10], the BPV analysis has prognostic value in other diseases like stroke [11,12], diabetes [13], chronic renal failure [14] or cognitive decline [15]. Thus is reflecting clinical relevance of BPV in cardiology with respect of autonomic control physiology and cardiac risk stratification [16].

According to the AHA/ACC Guidelines for prevention of sudden cardiac death both HRV and baroreflex sensitivity (BRS) analyses are promising methods for risk stratification. Additional studies are needed to further clarify the role of combining these methods in assessing risk in CHF.

\section{Methods}

88 cardiac patients of the Clinic of Internal Medicine I of the University Hospital of Jena, Germany (27 females, mean 66years 
Goernig et al. Cardiovascular System 2014,

http://www.hoajonline.com/journals/pdf/2052-4358-2-5.pdf

doi: 10.7243/2052-4358-2-5

and 61 males, mean 61years) with different degree of $\mathrm{CHF}$ ( 23 NYHA I, 53 NYHA II, 11 NYHA III, 1 NYHA IV) were included. The group consist of 58 patients with ischemic and 30 patients with none ischemic heart disease/cardiomyopathy. All patients had a history of at least one episode of acute heart failure and patients with preserved left ventricular ejection fraction had evidence of diastolic impairment assessed by echocardiography. High-resolution ECG (22 bit resolution, $1600 \mathrm{~Hz}$ sampling frequency) and continuous non-invasive blood pressure (NIBP, 22 bit, $500 \mathrm{~Hz}$ ) were recorded over 30 minutes under resting conditions using the Portapres non-invasive blood pressure monitor (TNO Biomedical Instrumentation, Netherlands). Based on volume clamp method the peripheral arterial blood pressure was measured via finger cuff [17]. Exclusion criteria were acute heart failure and known confounders of HRV analysis such as diabetes, atrial fibrillation, digitoxine and peripheral polyneuropathy as well as paced rhythm. Patients with a rate of arrhythmic beats over $10 \%$ were excluded from the study. From the ECG recordings, time series of beat-to-beat intervals were extracted to analyze HRV and from the NIBP recordings, time series of systolic as well as diastolic blood pressure values were extracted to analyze BPV. To get 'normal-to-normal' beat time series (NN), ventricular premature beats and artefacts within the time series were detected and replaced by interpolated heartbeats. Patients were divided in two groups: with left ventricular function above and below $40 \%$ (EF+ and EF-). For statistical analyses SPSS 14 was used: descriptive statistics (mean value, standard deviation), Pearson bivariate logistic correlation test, as well as the Mann-Whitney $\mathrm{U}$ test for the groups EF+ and EF- for clinical parameters (age, gender, BMI, medical treatment with ACE inhibitors, Beta blockers, LVEDD-left ventricular end diastolic diameter; LVEDP-left ventricular end diastolic pressure, QRS duration and NYHA class (I/II/III/IV) and standard (3) HRV (MEAN NN, SDNN, RMSSD, LF, HF, LF/HF, pNN50), diastolic and systolic BPV parameters (dMEAN NN, dSDNN, dLF, dHF, dLF/HF and sMEAN NN, sSDNN, sLF, sHF, sLF/HF) as well as bradyslope and tachyslope for BRS. The diagnostic power of BPV, HRV and BRS to separate the two groups was evaluated by using discrimination analyses. Additional discrimination analyses were applied to analyze 5-year follow up (cardiac death and worsening of NYHA class) for EF (echocardiography) and standard BPV and HRV parameters.

\section{Results and discussion}

According to the American Society of Echocardiography, an $\mathrm{EF} 30-44 \%$ is defined as medium range reduction of left ventricular function [18]. Up to now, the lower limit of normal in clinical practice has usually been set at $40 \%$ [19]. Therefore, we separated our CHF patients in two groups: a group with low EF (EF-) when the EF cut-off value was below $40 \%$ and a group with preserved $E F(E F+)$ when the cut-off value was equal or higher than $40 \%$. Descriptive statistics and univariate significances for the clinical parameters of EF+ and EF- are presented in Table 1. There are no significant differences in the clinical parameters age, gender, $\mathrm{BMI}$ and medical treatment and significant differences in NYHA class, LVEDD, LVEDP and QRS duration. Bivariate logistic correlation (Table 2) between the clinical parameters EF, NYHA class, LVEDD, LVEDP, QRS duration and BPV parameters showed significant results, but not between the HRV or BRS parameters. In Table 3, descriptive statistics and univariate significances for the HRV and BPV parameters are presented. From the HRV parameters only one (MEAN NN) but diastolic and systolic BPV parameters (dLF, dHF, dLF/HF and sLF, sHF, sLF/HF) separate $\mathrm{EF}+$ and EF-. In addition, none of the BRS parameters could separate the groups.

Table 1. Descriptive statistic and univariate significance of the clinical data of all patients and of subgroups with $\mathrm{EF}>\mathbf{4 0} \%(\mathrm{EF}+)$ and with $\mathrm{EF}<40 \%$ (EF-); $\mathrm{N}$-number of patients; mv-mean value; sd-standard deviation; BMI-body mass index; LVEDD-left ventricular end diastolic diameter; LVEDP-left ventricular end diastolic pressure; ACE-ACE inhibitors; BETA-Beta blockers.

\begin{tabular}{|c|c|c|c|c|c|}
\hline \multicolumn{6}{|c|}{ Clinical parameters of the study groups $\mathrm{EF}+(>40 \%)$ and $\mathrm{EF}-(<40 \%)$} \\
\hline \multirow{2}{*}{$\begin{array}{l}\text { Clinical } \\
\text { parameters }\end{array}$} & \multirow{2}{*}{$\begin{array}{l}\begin{array}{l}\text { All } \\
\text { patients } \\
(\mathrm{N}=88)\end{array} \\
63 \pm 12\end{array}$} & \multirow{2}{*}{$\begin{array}{l}\begin{array}{l}\mathrm{EF}+ \\
(\mathrm{N}=68)\end{array} \\
62 \pm 49\end{array}$} & \multirow{2}{*}{$\begin{array}{l}\begin{array}{l}\text { EF- } \\
(N=20)\end{array} \\
63 \pm 15\end{array}$} & \multicolumn{2}{|c|}{ P value } \\
\hline & & & & & 0.91 \\
\hline $\begin{array}{l}\text { Gender } \\
\text { (male/female) }\end{array}$ & $62 / 26$ & $46 / 22$ & $16 / 4$ & & 0.29 \\
\hline $\begin{array}{l}\mathrm{BMI}(\mathrm{mv} \pm \mathrm{sd}) \\
{\left[\mathrm{kg} / \mathrm{cm}^{2}\right]}\end{array}$ & $27.9 \pm 4.2$ & $28.6 \pm 4.6$ & $27.6 \pm 4.1$ & & 0,23 \\
\hline $\mathrm{EF}(\mathrm{mv} \pm \mathrm{sd})[\%]$ & $54 \pm 17$ & $60.4 \pm 10.8$ & $31.9 \pm 7.9$ & ** & $<0.001$ \\
\hline LVEDD $[\mathrm{mm}]$ & $53.8 \pm 9.7$ & $51.3 \pm 8.1$ & $61.4 \pm 10.5$ & ** & $<0.001$ \\
\hline LVEDP $[\mathrm{mmHg}]$ & $13.7 \pm 6.8$ & $16.7 \pm 8.2$ & $12.9 \pm 6.2$ & $* *$ & $<0.001$ \\
\hline QRS duration [ms] & $101.9 \pm 24.9$ & $96.4 \pm 22.8$ & $120.7 \pm 23.3$ & $* *$ & $<0.001$ \\
\hline $\begin{array}{l}\text { NYHA class } \\
\text { (I/II/III/IV) }\end{array}$ & $23 / 53 / 11 / 1$ & $23 / 43 / 2$ & 0/10/9/1 & $* *$ & $<0.001$ \\
\hline $\begin{array}{l}\text { ACE } \\
(\mathrm{N}, \text { percentage })\end{array}$ & $62(70 \%)$ & $44(65 \%)$ & $18(90 \%)$ & & 0.48 \\
\hline $\begin{array}{l}\text { BETA } \\
\text { (N, percentage) }\end{array}$ & $60(68 \%)$ & $42(62 \%)$ & $18(90 \%)$ & & 0.44 \\
\hline
\end{tabular}

univariate significance at the 0.05 level $\left(^{*}\right)$ and at the 0.01 level $\left({ }^{* *}\right)$.

In total, 16 patients died in the 5 year follow up period of acute heart failure or arrhythmic events. 5-year follow up showed significant results to predict cardiac death or worsening of NYHA class only with BPV parameters (Table 4). Combination of two systolic BPV parameters (sLF and sSDNN) could predict the worsening of NYHA class in $73.9 \%$ of the patients (positive predictive value $15 \%$, negative predictive value $91.2 \%$ ). Cardiac death was predicted in $81.8 \%$ of the patients using two diastolic BPV parameters (dLF/HF and dSDNN) resulting in a positive predictive value $12.5 \%$ and a negative predictive value of $97.2 \%$. The left ventricular EF, QRS-duration as well as standard HRV and BRS parameters had no significant prognostic value. 
Goernig et al. Cardiovascular System 2014,

http://www.hoajonline.com/journals/pdf/2052-4358-2-5.pdf

doi: $10.7243 / 2052-4358-2-5$

Table 2. Pearsons correlation between the clinical parameters (QRS duration, LVEDD, LVEDP, NYHA class, EF) and BPV parameters (sMEAN NN, sSDNN, sLF, sHF, sLF/HF and dMEAN NN, dSDNN, dLF, dHF, dLF/HF).

\begin{tabular}{|c|c|c|c|c|c|c|c|c|c|c|c|}
\hline \multicolumn{12}{|c|}{ Correlation between the clinical parameters and BPV parameters } \\
\hline Parameter & & $\begin{array}{l}\text { SMEAN } \\
\text { NN }\end{array}$ & sSDNN & $\mathbf{s L F} / \mathbf{H F}$ & sLF & sHF & $\begin{array}{l}\text { dMEAN } \\
\text { NN }\end{array}$ & dSDNN & dLF/HF & dLF & dHF \\
\hline \multirow[t]{2}{*}{ QRS-duration } & Pearson Correlation & 0.003 & 0.081 & 0.179 & $0.235(*)$ & $0.235(*)$ & 0.005 & 0.084 & 0.201 & $0.221\left(^{*}\right)$ & $0.221\left(^{*}\right)$ \\
\hline & Sig. (2-tailed) & 0.975 & 0.450 & 0.094 & 0.027 & 0.027 & 0.960 & 0.437 & 0.060 & 0.038 & 0.038 \\
\hline \multirow[t]{2}{*}{ LVEDD } & Pearson Correlation & $<0.001$ & 0.155 & $0.230\left(^{*}\right)$ & $0.264\left(^{*}\right)$ & $0.264\left(^{\star}\right)$ & 0.006 & 0.020 & $0.252\left(^{*}\right)$ & $0.267\left({ }^{*}\right)$ & $0.267\left(^{*}\right)$ \\
\hline & Sig. (2-tailed) & 0.997 & 0.158 & 0.034 & 0.014 & 0.014 & 0.960 & 0.858 & 0.020 & 0.014 & 0.014 \\
\hline \multirow[t]{2}{*}{ LVEDP } & Pearson Correlation & 0.043 & 0.010 & $0.248\left(^{*}\right)$ & 0.170 & 0.170 & 0.100 & 0.137 & 0.225 & $0.322\left(^{* *}\right)$ & $0.322\left({ }^{* *}\right)$ \\
\hline & Sig. (2-tailed) & 0.732 & 0.938 & 0.043 & 0.169 & 0.169 & 0.422 & 0.268 & 0.067 & 0.008 & 0.008 \\
\hline \multirow[t]{2}{*}{ NYHA } & Pearson Correlation & $0.220\left(^{*}\right)$ & 0.123 & $0.271\left(^{*}\right)$ & $0.261\left(^{*}\right)$ & $0.261\left(^{*}\right)$ & 0.191 & 0.009 & $0.311\left(^{* *}\right)$ & $\left.0.284{ }^{* *}\right)$ & $0.284\left({ }^{* *}\right)$ \\
\hline & Sig. (2-tailed) & 0.039 & 0.253 & 0.011 & 0.014 & 0.014 & 0.074 & 0.931 & 0.003 & 0.007 & 0.007 \\
\hline \multirow[t]{2}{*}{$\mathrm{EF}$} & Pearson Correlation & 0.087 & 0.152 & $\left.0.320{ }^{* *}\right)$ & $0.343\left(^{* *}\right)$ & $0.343\left(^{* *}\right)$ & 0.044 & 0.056 & $\left.0.300{ }^{* *}\right)$ & $0.350\left(^{* *}\right)$ & $0.350\left(^{* *}\right)$ \\
\hline & Sig. (2-tailed) & 0.423 & 0.161 & 0.003 & 0.001 & 0.001 & 0.686 & 0.605 & 0.005 & 0.001 & 0.001 \\
\hline
\end{tabular}

${ }^{\star}$ Correlation is significant at the 0.05 level (2-tailed), ${ }^{* *}$ Correlation is significant at the 0.01 level (2-tailed).

Table 3. Descriptive statistic and univariate significance of HRV and systolic and diastolic BPV parameters for the comparison of subgroups $\mathrm{EF}-(\mathrm{EF}<40 \%)$ and $\mathrm{EF}+(\mathrm{EF}>40 \%)$; mv-mean value; sd-standard deviation.

\begin{tabular}{|c|c|c|c|c|c|}
\hline \multicolumn{6}{|c|}{ HRV- and BPV parameters of the study groups $\mathrm{EF}+(>40 \%)$ and $\mathrm{EF}-(40 \%)$} \\
\hline Parameters & all patients & $\begin{array}{l}\mathrm{EF}+ \\
\mathrm{mv} \pm \mathrm{sd}\end{array}$ & $\begin{array}{l}\text { EF- } \\
\text { mv } \pm \text { sd }\end{array}$ & \multicolumn{2}{|c|}{ p value } \\
\hline \multicolumn{6}{|l|}{ HRV } \\
\hline MEAN NN [ms] & $843 \pm 104$ & $927 \pm 158$ & $855 \pm 128$ & ** & 0.008 \\
\hline SDNN $[\mathrm{ms}]$ & $38.8 \pm 18.2$ & $38.8 \pm 18.2$ & $35.4 \pm 20.3$ & & 0.32 \\
\hline \multicolumn{6}{|l|}{ Systolic BPV } \\
\hline sMEAN NN [mmHg] & $115 \pm 22$ & $115 \pm 22$ & $113 \pm 28$ & & 0.83 \\
\hline sSDNN [mmHg] & $0.9 \pm 0.3$ & $8.8 \pm 2.9$ & $0.8 \pm 03$ & & 0.35 \\
\hline $\mathrm{sLF}\left[\mathrm{mmHg}^{2}\right]$ & $6.3 \pm 1.4$ & $6.5 \pm 1.3$ & $5.3 \pm 1.4$ & ** & $<0.001$ \\
\hline $\mathrm{sHF}\left[\mathrm{mmHg}^{2}\right]$ & $3.7 \pm 1.4$ & $3.4 \pm 1.3$ & $4.6 \pm 1.4$ & ** & $<0.001$ \\
\hline sLF/HF [-] & $2.0 \pm 1.1$ & $2.2 \pm 1.0$ & $1.5 \pm 1.2$ & ** & $<0.001$ \\
\hline \multicolumn{6}{|l|}{ Diastolic BPV } \\
\hline dMEAN NN [mmHg] & $54 \pm 13$ & $54 \pm 0.12$ & $52 \pm 1.6$ & & 0.55 \\
\hline dSDNN [mmHg] & $3.8 \pm 1.4$ & $3.8 \pm 1.4$ & $3.7 \pm 1.5$ & & 0.85 \\
\hline $\mathrm{dLF}\left[\mathrm{mmHg}^{2}\right]$ & $7.4 \pm 1.3$ & $7.6 \pm 1.1$ & $6.6 \pm 1.4$ & ** & 0.005 \\
\hline $\mathrm{dHF}\left[\mathrm{mmHg}^{2}\right]$ & $2.6 \pm 1.3$ & $2.4 \pm 1.1$ & $3.4 \pm 1.4$ & ** & 0.005 \\
\hline dLF/HF [-] & $3.7 \pm 2.2$ & $4.0 \pm 2.1$ & $2.6 \pm 2.0$ & ** & 0.005 \\
\hline
\end{tabular}

univariate significance at the 0.05 level $\left(^{*}\right)$ and at the 0.01 level $\left(^{* *}\right)$.

In Table 5 correlation between HRV and BPV parameters were shown. Only two BPV parameters showed a significant correlation with HRV indices (dMEAN NN and MEAN NN, $\mathrm{dLF} / \mathrm{HF}$ and SDNN). All other BPV parameters included no significant correlated information to the chosen standard HRV parameters MEAN NN and SDNN.

Altered blood pressure regulation plays a central role in the pathophysiology of CHF. Beside restriction of physical ability, disturbed orthostatic blood pressure regulation with cerebral perfusion deficiency and dizziness is an early symptom of CHF. In this study, impaired HRV seen as reduced MEAN NN, could be demonstrated in the subgroup EF-. Reduced sympathetic (dLF) and elevated vagal (dHF) components of diastolic blood pressure regulation were typical for patients with advanced 
Goernig et al. Cardiovascular System 2014,

http://www.hoajonline.com/journals/pdf/2052-4358-2-5.pdf

doi: $10.7243 / 2052-4358-2-5$

Table 4. Chi-Square test between BPV parameters (dMEAN NN, dSDNN, dLF, dHF, dLF/HF and sMEAN NN, sSDNN, sLF, sHF, sLF/HF) and surviver vs. cardiac death after 5 years (left) and worsening vs. no worsening of NYHA class after 5 years (right).

\begin{tabular}{|c|c|c|c|c|c|c|c|c|}
\hline \multicolumn{9}{|c|}{ BPV parameters and 5 year follow up (cardiac death and worsening of NYHA class) } \\
\hline Parameters & & Cardiac Death & \multicolumn{2}{|c|}{ p value } & $\begin{array}{l}\text { No worsening of NYHA } \\
\text { class } \\
\mathrm{n}=68 \\
\mathrm{mv} \pm \mathrm{sd}\end{array}$ & $\begin{array}{l}\text { Worsening of NYHA class } \\
\mathrm{n}=20 \\
\mathrm{mv} \pm \mathrm{sd}\end{array}$ & \multicolumn{2}{|c|}{ p value } \\
\hline sMEAN NN [ms] & $115.7 \pm 22.3$ & $110.3 \pm 21.7$ & & 0.374 & $113.7 \pm 23.7$ & $118 \pm 15.9$ & & 0.449 \\
\hline sSDNN & $9.0 \pm 2.9$ & $7.8 \pm 2.4$ & * & 0.018 & $8.4 \pm 2.8$ & $10.1 \pm 2.6$ & * & 0.014 \\
\hline $\mathrm{sLF}\left[\mathrm{mmHg}^{2}\right]$ & $6.3 \pm 1.3$ & $5.7 \pm 1.1$ & & 0.056 & $6.1 \pm 1.5$ & $6.9 \pm 0.7$ & $* *$ & 0.010 \\
\hline $\mathrm{sHF}\left[\mathrm{mmHg}^{2}\right]$ & $3.6 \pm 1.4$ & $4.3 \pm 1.1$ & & 0.056 & $3.9 \pm 1.5$ & $3.1 \pm 0.7$ & $* *$ & 0.010 \\
\hline sLF/HF [-] & $2.2 . \pm 1.1$ & $1.5 \pm 0.7$ & * & 0.023 & $1.9 . \pm 1.1$ & $2.5 \pm 0.8$ & * & 0.041 \\
\hline \multicolumn{9}{|l|}{ Diastolic BPV } \\
\hline dMEAN NN [ms] & $55.8 \pm 12.8$ & $48 \pm 11.8$ & * & 0.028 & $53.8 \pm 13.5$ & $56.2 \pm 10.7$ & & 0.475 \\
\hline dSDNN & $4.0 \pm 1.5$ & $3.2 \pm 0.9$ & * & 0.048 & $10.8 \pm 3.7$ & $4.1 . \pm 1.0$ & & 0.389 \\
\hline $\mathrm{dLF}\left[\mathrm{mmHg}^{2}\right]$ & $7.5 \pm 1.2$ & $6.6 \pm 1.3$ & ** & 0.009 & $7.2 \pm 1.3$ & $7.8 \pm 1.1$ & * & 0.041 \\
\hline $\mathrm{dHF}\left[\mathrm{mmHg}^{2}\right]$ & $2.4 \pm 1.2$ & $3.4 \pm 1.3$ & ** & 0.009 & $2.8 \pm 1.3$ & $2.1 \pm 1.1$ & * & 0.041 \\
\hline dLF/HF [-] & $4.0 \pm 2.3$ & $2.4 \pm 1.1$ & $* *$ & 0.006 & $3.4 \pm 2.1$ & $4.8 \pm 2.4$ & * & 0.027 \\
\hline
\end{tabular}

univariate significance at the 0.05 level $\left(^{*}\right)$ and at the 0.01 level $\left(^{* *}\right)$.

Table 5. Pearsons correlation between the HRV- (MEAN NN, SDNN) and BPV parameters (sMEAN NN, sSDNN, sLF, sHF, sLF/HF and dMEAN NN, dSDNN, dLF, dHF, dLF/HF), $n=88$.

\begin{tabular}{|c|c|c|c|}
\hline \multicolumn{4}{|c|}{ Correlation between HRV- and BPV parameters } \\
\hline & & MEAN NN & SDNN \\
\hline \multirow[t]{2}{*}{ sMEAN NN } & Pearson Correlation & -0.203 & -0.030 \\
\hline & Sig. (2-tailed) & 0.119 & 0.779 \\
\hline \multirow[t]{2}{*}{ sSDNN } & Pearson Correlation & 0.005 & 0.089 \\
\hline & Sig. (2-tailed) & 0.971 & 0.408 \\
\hline \multirow[t]{2}{*}{ dMEAN NN } & Pearson Correlation & $\left.-0.4311^{* *}\right)$ & -0.095 \\
\hline & Sig. (2-tailed) & 0.001 & 0.380 \\
\hline \multirow[t]{2}{*}{ dSDNN } & Pearson Correlation & 0.100 & 0.081 \\
\hline & Sig. (2-tailed) & 0.445 & 0.455 \\
\hline \multirow[t]{2}{*}{$\mathrm{sLF} / \mathrm{HF}$} & Pearson Correlation & -0.002 & 0.044 \\
\hline & Sig. (2-tailed) & 0.987 & 0.684 \\
\hline \multirow[t]{2}{*}{ sLF } & Pearson Correlation & -0.017 & 0.023 \\
\hline & Sig. (2-tailed) & 0.897 & 0.831 \\
\hline \multirow[t]{2}{*}{ sHF } & Pearson Correlation & 0.017 & -0.023 \\
\hline & Sig. (2-tailed) & 0.897 & 0.831 \\
\hline \multirow[t]{2}{*}{$\mathrm{dLF} / \mathrm{HF}$} & Pearson Correlation & 0.157 & $0.234\left(^{*}\right)$ \\
\hline & Sig. (2-tailed) & 0.230 & 0.028 \\
\hline \multirow[t]{2}{*}{$\mathrm{dLF}$} & Pearson Correlation & 0.154 & 0.187 \\
\hline & Sig. (2-tailed) & 0.240 & 0.081 \\
\hline \multirow[t]{2}{*}{$\mathrm{dHF}$} & Pearson Correlation & -0.154 & -0.187 \\
\hline & Sig. (2-tailed) & 0.240 & 0.081 \\
\hline
\end{tabular}

** Correlation is significant at the 0.01 level (2-tailed). Correlation is significant at the 0.05 level (2-tailed). heart failure. The diastolic blood pressure regulation is more sensitive to impaired autonomic control as systolic blood pressure regulation, which is stronger affected by other factors like vascular elasticity and diameter or peripheral resistance.

In this study, we used non-invasive continuous blood pressure analysis at resting conditions performed during daytime. Thus offers the possibility to compare beat to beat HRV and BPV directly. Current studies showed hour to hour and even visit to visit blood pressure variability as predictors of incident cardiovascular events [20].

In 2010 Hansen et al., on behalf of the International Database on Ambulatory Blood Pressure in Relation to Cardiovascular Outcomes Investigators showed diastolic (dSDNN) but not systolic blood pressure variability alone predictive for cardiovascular events combined with fatal plus nonfatal stroke [22]. Recently also a large community-based cross-sectional study among Japanese men and women suggested that HRV reflects diastolic blood pressure better than systolic blood pressure levels for both sexes [21].

Extreme short time variations of arterial blood pressure are counter-regulated by the baroreflex, stabilizing the pressure within upper and lower limits. HRV and BPV are directly linked over BRS: reduced HRV is combined with reduced BRS and leads to increased BPV. All three are reflecting the condition of autonomic control.

The diagnostic power of the HRV analysis was not high enough to separate CHF patients with EF+ and EF-. Beside MEAN NN, none of the calculated HRV parameters showed significant results in separation of the groups, also none of the BRS parameters. In contrast, systolic and diastolic BPV 
parameters could contribute a high significant separation between EF+ and EF-. Moreover, BPV parameters predict the 5 -year prognoses of cardiac death and worsening of NYHA class in CHF. HRV and BRS analysis showed no significant result in 5-year risk stratification.

Whereas impaired $\mathrm{EF}$ is the main risk factor in $\mathrm{CHF}$ and is correlated to BPV parameters in this study, the 5-year prognosis could not be predicted by EF alone neither by QRS duration. Thus is also indicating an advantaged diagnostic power of BPV analysis in CHF.

Our data could confirm the value of BPV in risk stratification of heart failure patients. Dynamics of blood pressure regulation were shown before significantly changed in dilated cardiomyopathy (DCM) comparing continuous noninvasive blood pressure and high-resolution electrocardiogram from 91 DCM patients during a median follow-up period of 28 months (8). Diastolic BPV indexes, especially those from symbolic dynamics, appear to be useful for risk stratification of sudden cardiac death in patients with DCM. As well, linear HRV and BPV analysis, short-term nonlinear methods as symbolic dynamics (STSD), detrended fluctuation (DFA), and Poincare plot analysis (PPA) were compared. Measures from BPV analysis, $D F A$, and PPA revealed highly significant differences $(p<0.0011)$ discriminating DCM and healthy subjects. It could be shown that parameters from BPV analysis enhanced risk stratification in DCM patients even better than standard HRV parameters. For risk stratification in DCM patients, four parameters from BPV analysis, STSD, and PPA revealed significant differences between low and high risk (maximum sensitivity: $90 \%$, specificity: 90\%) [23].

\section{Conclusion}

Our results suggest that the analysis of autonomic control should focus more on blood pressure regulation. BPV analysis can be as easily performed as HRV from 24-hour Holter ECG recordings. Continuous analysis of arterial blood pressure by finapres and portapres systems-a non-invasive and easy to perform technique-is a promising method open for the clinical routine in cardiac event risk stratification. BPV parameters may be useful in medium range risk stratification in patients with chronic cardiac diseases such as CHF.

\section{Competing interests}

The authors declare that they have no competing interests.

Authors' contributions

\begin{tabular}{|l|c|c|c|c|c|c|}
\hline Authors' contributions & GE & RS & RK & HRF & AV & UL \\
\hline Research concept and design & -- & $\checkmark$ & $\checkmark$ & -- & $\checkmark$ & $\checkmark$ \\
\hline Collection and/or assembly of data & -- & $\checkmark$ & $\checkmark$ & -- & -- & $\checkmark$ \\
\hline Data analysis and interpretation & $\checkmark$ & $\checkmark$ & $\checkmark$ & $\checkmark$ & $\checkmark$ & $\checkmark$ \\
\hline Writing the article & $\checkmark$ & -- & -- & -- & -- & $\checkmark$ \\
\hline Critical revision of the article & -- & $\checkmark$ & -- & $\checkmark$ & $\checkmark$ & $\checkmark$ \\
\hline Final approval of article & $\checkmark$ & -- & -- & -- & -- & $\checkmark$ \\
\hline Statistical analysis & $\checkmark$ & -- & -- & -- & -- & $\checkmark$ \\
\hline
\end{tabular}

\section{Publication history}

Editors: Valery I. Kapelko, Russian Cardiological Complex, Russia.

Felipe A. Martinez, Cordoba National University, Argentina.

Received: 28-Mar-2014 Final Revised: 08-May-2014

Accepted: 14-May-2014 Published: 30-May-2014

\section{References}

1. Benatar D, Bondmass $M$, Ghitelman J and Avitall B. Outcomes of chronic heart failure. Arch Intern Med. 2003; 163:347-52. | Article | PubMed

2. Fonarow GC, Albert NM, Curtis AB, Gheorghiade M, Heywood JT, Liu Y, Mehra MR, O'Connor CM, Reynolds D, Walsh MN and Yancy CW. Associations between outpatient heart failure process-of-care measures and mortality. Circulation. 2011; 123:1601-10. | Article | PubMed

3. Theuns DA, Smith T, Hunink MG, Bardy GH and Jordaens L. Effectiveness of prophylactic implantation of cardioverter-defibrillators without cardiac resynchronization therapy in patients with ischaemic or non-ischaemic heart disease: a systematic review and meta-analysis. Europace. 2010; 12:1564-70. | Article | PubMed Abstract | PubMed Full $\underline{\text { Text }}$

4. Heart rate variability: standards of measurement, physiological interpretation and clinical use. Task Force of the European Society of Cardiology and the North American Society of Pacing and Electrophysiology. Circulation. 1996; 93:1043-65. | Article | PubMed

5. Siche JP, Herpin D, Asmar RG, Poncelet P, Chamontin B, Comparat V, Gressin V, Boutelant $S$ and Mallion JM. Non-invasive ambulatory blood pressure variability and cardiac baroreflex sensitivity. J Hypertens. 1995; 13:1654-9. | PubMed

6. Stauss HM. Identification of blood pressure control mechanisms by power spectral analysis. Clin Exp Pharmacol Physiol. 2007; 34:362-8. Article | PubMed

7. Voss A, Schroeder R, Truebner S, Baumert M, Goernig M, Hagenow A and Figulla HR. Multivariate and multidimensional analysis of cardiovascular oscillations in patients with heart failure. Biomed Tech (Berl). 2006; 51:163-6. | Article | PubMed

8. Voss A, Goernig M, Schroeder R, Truebner S, Schirdewan A and Figulla HR. Blood pressure variability as sign of autonomic imbalance in patients with idiopathic dilated cardiomyopathy. Pacing Clin Electrophysiol. 2012; 35:471-9. | Article | PubMed

9. Zipes DP, Camm AJ, Borggrefe M, Buxton AE, Chaitman B, Fromer $M$ Gregoratos G, Klein G, Moss AJ and Myerburg RJ. ACC/AHA/ESC 2006 Guidelines for Management of Patients With Ventricular Arrhythmias and the Prevention of Sudden Cardiac Death: a report of the American College of Cardiology/American Heart Association Task Force and the European Society of Cardiology Committee for Practice Guidelines (writing committee to develop Guidelines for Management of Patients With Ventricular Arrhythmias and the Prevention of Sudden Cardiac Death): developed in collaboration with the European Heart Rhythm Association and the Heart Rhythm Society. Circulation. 2006; 114:e385484. | Article | PubMed

10. Malberg H, Wessel N, Hasart A, Osterziel KJ and Voss A. Advanced analysis of spontaneous baroreflex sensitivity, blood pressure and heart rate variability in patients with dilated cardiomyopathy. Clin Sci (Lond). 2002; 102:465-73. | Article | PubMed

11. Pringle E, Phillips C, Thijs L, Davidson C, Staessen JA, de Leeuw PW, Jaaskivi M, Nachev C, Parati G, O’Brien ET, Tuomilehto J, Webster $\mathrm{J}$, Bulpitt $\mathrm{CJ}$ and Fagard RH. Systolic blood pressure variability as a risk factor for stroke and cardiovascular mortality in the elderly hypertensive population. J Hypertens. 2003; 21:2251-7. | Article | PubMed

12. Lau KK, Wong YK, Chang RS, Teo KC, Hon SF, Chan KH, Wat KL, Cheung RT, Li LS, Siu CW, Ho SL and Tse HF. Visit-to-visit systolic blood pressure variability predicts all-cause and cardiovascular mortality after lacunar infarct. Eur J Neurol. 2014; 21:319-25. | Article | PubMed

13. Ciobanu AO, Gherghinescu CL, Dulgheru R, Magda S, Dragoi Galrinho $R$, Florescu M, Guberna S, Cinteza M and Vinereanu D. The impact of blood pressure variability on subclinical ventricular, renal and vascular 
Goernig et al. Cardiovascular System 2014,

http://www.hoajonline.com/journals/pdf/2052-4358-2-5.pdf

dysfunction, in patients with hypertension and diabetes. Maedica

(Buchar). 2013; 8:129-36. | PubMed Abstract | PubMed Full Text

14. Selvarajah V, Pasea L, Ojha S, Wilkinson IB and Tomlinson LA. Pre-dialysis systolic blood pressure-variability is independently associated with allcause mortality in incident haemodialysis patients. PLoS One. 2014 28; 9:e86514. | Article

15. Matsumoto $A$, Satoh $M$, Kikuya $M$, Ohkubo T, Hirano $M$, Inoue $R$, Hashimoto T, Hara A, Hirose T, Obara T, Metoki H, Asayama K, Hosokawa A, Totsune K, Hoshi H, Hosokawa T, Sato H and Imai Y. Day-to-Day Variability in Home Blood Pressure Is Associated With Cognitive Decline: The Ohasama Study. Hypertension. 2014; 63:1333-8. | Article | PubMed

16. Rothwell PM. Limitations of the usual blood-pressure hypothesis and importance of variability, instability, and episodic hypertension. Lancet. 2010; 375:938-48. | Article | PubMed

17. Langewouters GJ, Settels JJ, Roelandt R and Wesseling KH. Why use Finapres or Portapres rather than intra-arterial or intermittent noninvasive techniques of blood pressure measurement? J Med Eng Technol. 1998; 22:37-43. | Article | PubMed

18. Lang RM, Bierig M, Devereux RB, Flachskampf FA, Foster E, Pellikka PA, Picard MH, Roman MJ, Seward J, Shanewise JS, Solomon SD, Spencer KT, Sutton MS and Stewart WJ. Recommendations for chamber quantification: a report from the American Society of Echocardiography's Guidelines and Standards Committee and the Chamber Quantification Writing Group, developed in conjunction with the European Association of Echocardiography, a branch of the European Society of Cardiology. J Am Soc Echocardiogr. 2005; 18:144063. | Article | PubMed

19. Mahadevan G, Davis RC, Frenneaux MP, Hobbs FD, Lip GY, Sanderson JE and Davies MK. Left ventricular ejection fraction: are the revised cut-off points for defining systolic dysfunction sufficiently evidence based? Heart. 2008; 94:426-8. | Article | PubMed

20. Eguchi K, Hoshide S, Schwartz JE, Shimada K and Kario K. Visit-to-visit and ambulatory blood pressure variability as predictors of incident cardiovascular events in patients with hypertension. Am J Hypertens. 2012; 25:962-8. | Article | PubMed Abstract | PubMed Full Text

21. Hansen TW, Thijs L, Li Y, Boggia J, Kikuya M, Bjorklund-Bodegard K, Richart T, Ohkubo T, Jeppesen J and Torp-Pedersen C. Prognostic value of reading-to-reading blood pressure variability over 24 hours in 8938 subjects from 11 populations. Hypertension. 2010; 55:1049-57. | Article I PubMed

22. Mori H, Saito I, Eguchi E, Maruyama K, Kato T and Tanigawa T. Heart rate variability and blood pressure among Japanese men and women: a community-based cross-sectional study. Hypertens Res. 2014. | Article I PubMed

23. Voss A, Schroeder R, Truebner S, Goernig M, Figulla HR and Schirdewan A. Comparison of nonlinear methods symbolic dynamics, detrended fluctuation, and Poincare plot analysis in risk stratification in patients with dilated cardiomyopathy. Chaos. 2007; 17:015120. | Article | PubMed

\section{Citation:}

Goernig M, Schroeder R, Kleindienst R, Figulla HR, Voss A and Leder U. Blood pressure variability analysis enhances risk stratification in chronic heart failure. Cardio Vasc Syst. 2014; 2:5.

http://dx.doi.org/10.7243/2052-4358-2-5 